\title{
CMA's agenda swells in wake of Annual Meeting
}

$\mathrm{D}$ ealing with the health effects of climate change, leading integrated care, weighing in on the new Health Accord and setting parameters for the legalization of marijuana are among the many issues facing the Canadian Medical Association (CMA) following its 149th Annual Meeting, in Vancouver Aug. 21-24.

Leading CMA's agenda at the onset of the meeting was the need for a financial top-up to help provinces and territories pay for the additional health costs of an aging population. The call was bolstered by a CMA-sponsored Ipsos Reid poll indicating $74 \%$ of Canadians support the top-up, estimated to cost $\$ 1.6$ billion.

But federal Health Minister Dr. Jane Philpott was adamant in her address to the 265 delegates that a federal cash injection won't fix Canada's health system. "This year, the Canada Health Transfer reached an historic high of over \$36 billion, but I am firmly convinced that we have an obligation as a federal government to do more than simply open up the federal wallet," Philpott said.

Upcoming negotiations for a new health care accord between the federal government, provinces, and territories present a "rare opportunity" to reshape the system to meet the demands of an aging population, she added.

The Health Accord is slated to be in place early in 2017 and CMA's new president, Dr. Granger Avery is ready for the negotiations to begin. Avery, who has spent four decades in family practice in remote Port McNeill, British Columbia, worked on the previous accord.

Doctors need to stop fighting with governments and among themselves, and start thinking collaboratively to improve health care in Canada, Avery said in his inaugural address to delegates.

"If we are going to seize this moment in time and actually bring about the crucial changes to our health care system ... we will need to do it by working together," he said. "We must not succumb to polarization and infighting."

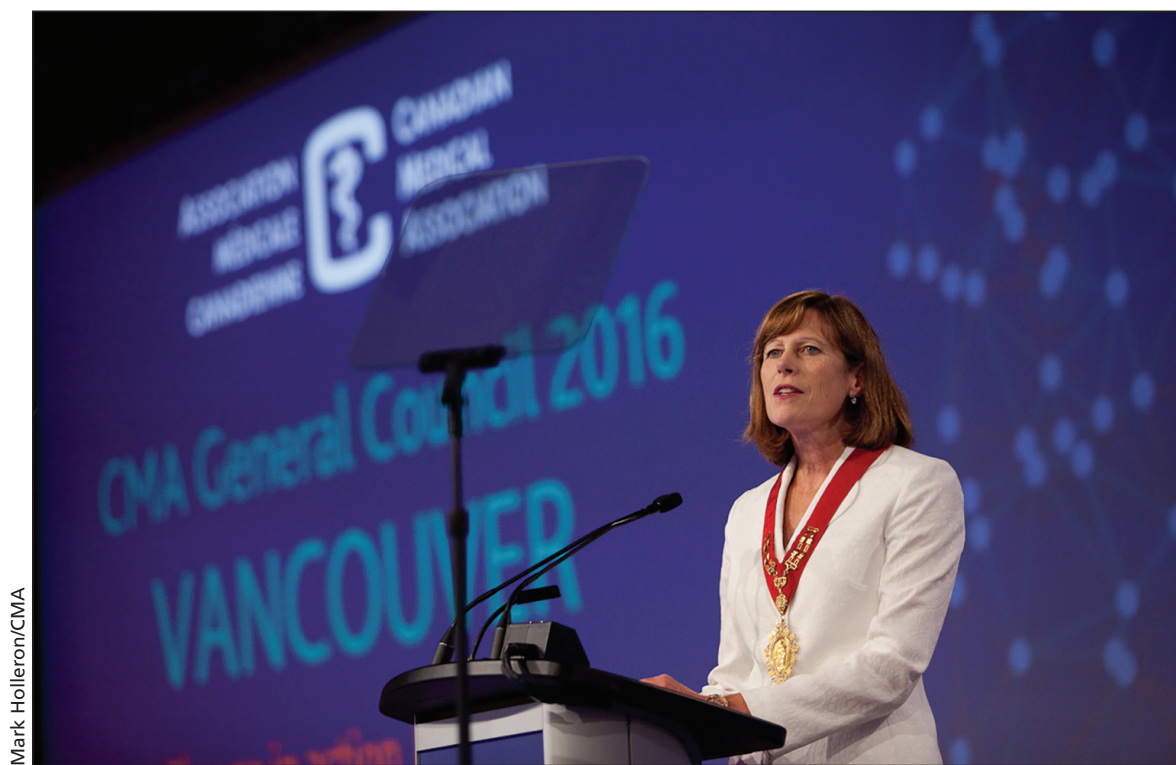

Dr. Cindy Forbes, CMA's outgoing president, made a heartfelt case at the annual meeting for professional unity in the face of adversity and challenges.

\section{Vaccine exemptions}

There was plenty of disagreement among delegates who narrowly approved $(58 \%)$ a motion to support the elimination of nonmedical exemptions for vaccination in Ontario, New Brunswick and Manitoba, where children must be vaccinated in order to attend school.

Former CMA president, Dr. Anna Reid, said evidence from the United States indicates mandatory vaccination can lead to decreased vaccination rates. The small population opposed to vaccines becomes more strident, "and that spreads to people sitting on the fence," said Reid.

\section{Integrated system}

CMA was also tasked with providing guidance on integrating Canada's fragmented health system. According to a CMA report, integrated care provides an accessible and seamless experience for the patient in a financially prudent manner.

"To move to integrated care, we need to shift from viewing health care as a commodity that is produced by providers in a system managed by providers, to a collection of services, coproduced by patients and providers, based on values of the patients in a coordinated system. And this is the path to patient-centered integration," said Dr. Carl Nohr, president of the Alberta Medical Association.

"The CMA has a really integral role to play ... to create the single unified vision that will be a tremendously useful catalyst for change in the country," said CMA Board Member Dr. Pierre Harvey of Quebec.

\section{New president-elect}

Such a challenge will undoubtedly persist when Dr. Laurent Marcoux from Longueuil, Quebec, takes over as president in August 2017. Marcoux, who was declared president-elect during the meeting, has practised family medicine for 32 years. He said that experience taught him not only the importance of the doctor-patient relationship, but also helped him understand the organizational difficulties in the medical profession.

"Renewed professionalism is clearly needed, as society expects us to act as stewards of the common good and ensure the sustainability of our health care system," said Marcoux. 


\section{Professional unity}

In her valedictory address, CMA's outgoing President Dr. Cindy Forbes also spoke about professionalism in the face of sometimes hostile governments, pressure-cooker schedules and continually changing technology.

"How will we move forward?" asked Forbes. "We will stand together as a profession, based on our common values, always putting patients first. We will support and respect each other as individuals, as colleagues who we care about. We will build trust by being trustworthy."

\section{Doctor burnout}

Physicians also took time to focus on their health during a session on strengthening resilience. Physicians can experience burnout, or other mental health problems, at any stage in their careers, said presenters.

Marie-Pier Bastrash, a medical student at McGill University presented preliminary results from a survey of 5000 medical students that indicated around $37 \%$ are burned out. It also found they have higher rates of anxiety and mood disorders than peers of similar age and education.

Delegates passed a motion asking CMA to undertake a nationwide study to analyze the working and practice conditions of medical students and residents.

\section{Climate change}

The annual meeting began with a plea from humanitarian Dr. James Orbinski, who presented a grim picture of the health effects of climate change. The cofounder of Médecins Sans Frontières Canada urged CMA to "step up and step out, to be genuinely courageous on climate change." Doctors have a professional responsibility to get involved, he added.

Forbes rose to the challenge, promising that by the 2017 annual meeting, CMA will be "well on its way to estab- lishing a new role in dealing with climate change."

\section{On legal pot}

Recreational marijuana is slated to be legal in 2017 and doctors want the federal government to keep it out of the hands of teenagers, according to the results of a CMA survey of 788 doctors presented at the meeting.

Nearly three out of four respondents $(72.2 \%)$ agreed the government should regulate levels of tetrahydrocannabinol in marijuana once the drug is legalized. Most respondents also agreed that nonhealth care structures like liquor stores should distribute the drug (56.1\%), and disagreed with providing the drug through health care settings like pharmacies $(57.4 \%)$ or by mail (64.9\%).

Go to cmajnews.com for complete coverage of the CMA Annual Meeting. - Barbara Sibbald, CMAJ

CMAJ 2016. DOI:10.1503/cmaj.109-5321

\section{Misconduct saga rattles bone scientists}

I n a saga that has shaken scientists who study bone health, the Canadian Institutes of Health Research (CIHR) has ruled that a University of Toronto medical school professor is guilty of a serious breach of federal research rules.

A committee appointed by Women's College Hospital in Toronto found that Dr. Sophie Jamal manipulated trial data to make the results look better, presented manipulated data to coinvestigators as if they were raw data, falsely accused a research assistant of manipulating data, and deleted records required for the hospital's forensic investigation. Jamal was the hospital's head of endocrinology and director of osteoporosis research until she resigned from the hospital and the university last year.

This is the first time a federal funding agency has named a scientist for a breach of the TriAgency Framework: Responsible Conduct of Research since the framework took effect in December 2011. CIHR also banned Jamal for life from receiving funds; she is the sixth scientist to receive a lifetime ban because of research violations.
Coauthors have so far retracted two papers on which she was an author, and have asked a journal to retract another. A university committee is reviewing as many as 50 other articles. One retraction notice said Jamal had "declined to provide any comments." She did not respond to interview requests from $C M A J$.

Some colleagues are skeptical about the ruling. "We all know Sophie; we all work with her; we all thought she was of high moral standing and had high ethics," said Dr. Thomas Nickolas, a kidney specialist at Columbia University College of Physicians and Surgeons in New York City.

Dr. David Goltzman, a senior scientist at McGill University, who led a long-term study underlying one of the retracted articles, called Jamal "extremely well-trained, extremely talented," and said the situation is "tragic."

The Women's College investigation focused on a study testing the effects of different nitrate drugs on bone health, an area Jamal had worked in since the 1990s when she was at the University of California, San Francisco (UCSF). Early on, reviewing data that others had gathered, she discovered that women taking nitrate drugs had higher bone densities, a finding she published in 1998 with UCSF's Dr. Steven Cummings, a leader in osteoporosis research and her mentor.

Apart from the stint at UCSF, Jamal did nearly all of her training at the University of Toronto and returned there to continue her research. Her first trial to test a nitrate drug against placebo, published in 2004 in the Journal of Bone and Mineral Research, had positive findings that suggested nitrates may be useful for the prevention of postmenopausal osteoporosis.

By the late 2000s, the search for a safer drug for women with fragile bones was pressing because of emerging information about the risks of drugs typically prescribed for osteoporosis. Jamal's next trial with nitrates resulted in her highestprofile publication, a 2011 paper in the Journal of the American Medical Association (JAMA). With Cummings and Dr. Richard Eastell, an osteoporosis 